\title{
TRILHA DAS FUNÇÕES ORGÂNICAS: UM JOGO DIDÁTICO PARA O ENSINO DE QUIIMICA
}

\author{
Eciângela Ernesto Borges ${ }^{1}$, Maria Mozarina Beserra Almeida ${ }^{1}$, \\ Isaías Batista De Lima ${ }^{2}$, Paulo Henrique Machado de Sous ${ }^{1}$ \\ ${ }^{1}$ Universidade Federal do Ceará (UFC) \\ ${ }^{2}$ Universidade Estadual do Ceará (UECE) \\ <eciborges@hotmail.com>,<mozarina@gmail.com>. \\ <isaiasblima@yahoo.com.br>.<phenriquemachado@gmail.com>
}

DOI: $10.21439 /$ conexoes.v10i4.1026

\begin{abstract}
Resumo. O Ensino de Química aplicado nas escolas é identificado como tradicional, abstrato e descontextualizado, desestimulando, assim, o interesse de muitos estudantes pela disciplina de Química. O presente trabalho teve como objetivo elaborar, aplicar e analisar a contribuição do jogo didático "Trilha das Funções Orgânicas" como uma ferramenta pedagógica para auxiliar no estudo das funções orgânicas de forma lúdica e interativa. Este trabalho foi realizado através de uma pesquisa de natureza descritiva, de cunho qualiquantitativo, de campo e desenvolvida com 21 alunos de uma turma de $3^{\circ}$ ano do ensino médio na E.E.F.M. Professor Paulo Freire, localizada em Fortaleza-CE. Um dos instrumentos utilizados para avaliar o uso do jogo foi um questionário aplicado após a utilização desse jogo em sala de aula. Os resultados obtidos através das observações e do questionário aplicado indicaram que o jogo atuou como um instrumento facilitador e eficiente na compreensão do referido conteúdo. Constatou-se ainda que, o uso do jogo didático "Trilha das Funções Orgânicas" proporcionou a participação e a interação entre os alunos, podendo potencializar a promoção de uma aprendizagem prazerosa e eficaz. Entretanto, o educador deve ter a capacidade de conhecer e identificar as vantagens e desvantagens na proposta da aplicação de jogos na sua prática de ensino, adaptando-os aos conteúdos a serem abordados e à realidade da escola.
\end{abstract}

Palavras-chaves: Ensino de Química. Jogo Didático. Funções Orgânicas.

Abstract. The Chemistry Teaching applied in schools has been recognized as traditional, abstract and out of context,thusdiscouraging interest of many students in studying Chemistry.This study has aimed to formulate, implement and analyze the contribution of the educational game Trilha das FunçõesOrgânicas(Organic Functions Track- OFT) - as a pedagogical tool to assist the organic functions studies in a playful and interactive way. This paper has been written through a descriptive research on quantitative and qualitative approach as fieldwork. It was developed at EEFM Professor Paulo Freire School, located in Fortaleza City- Brazil. The corpus was given by twenty-one students from the third period of a regular high school class. One of the tools used to evaluate the use of the game was a questionnaire applied after its use in the classroom. The results gotten through class observations and the applied questionnaire have shown that the game worked as a facilitator and efficient tool in the students' understanding of that content. It has also been found that the use of the educational game OFT provided the participation and interaction among students, enhancing the promotion of enjoyable and effective learning. However, the teacher must be able to know and identify the advantages and disadvantages of applying games in teaching practice, adapting them to the studied contents and to the reality of the school.

Keywords: Chemistry Teaching. Didactic Game. Organic Functions. 


\section{INTRODUÇÃO}

O Ensino de Química, atualmente, ainda é apresentado de forma tradicional e descontextualizado, sobretudo no ensino médio. De acordo com os pesquisadores Cardoso e Colinvaux (2000), a forma como os professores ministram a disciplina de Química em sala de aula, desestimula o interesse dos alunos pela Química, visto que a quantidade excessiva de conteúdos, na maioria das vezes abstratos e descontextualizados, torna essa disciplina enfadonha e sem significado para o aluno.

O docente de Química reconhece a existência de dificuldades de aprendizagem e resistência por parte dos estudantes ao ensino dessa disciplina na forma tradicional que, nas últimas décadas, visa prioritariamente à aprovação em vestibulares.

Diante disso, faz-se necessário que o educador utilize metodologias diferenciadas com a finalidade de tornar as aulas de Química mais dinâmicas, prazerosas e significativas para o alunado. É nesse contexto que os jogos didáticos ganham espaço, como instrumentos lúdicos e motivadores para a aprendizagem de conceitos químicos presentes no currículo escolar, à medida que se propõe estímulo ao interesse do docente. A prática de atividades lúdicas impulsiona as funções psiconeurológicas e os processos psíquicos. No momento em que joga, o educando transforma-se em sujeito ativo do processo de ensino e aprendizagem no qual está incluído, isto é, ele assimila os conhecimentos à medida que brinca. $\mathrm{O}$ processo de aprendizagem é influenciado diretamente pelas atividades lúdicas, já que estas atividades compõem e acionam os campos motor, cognitivo e afetivos dos indivíduos (SANTANA; WARTHA, 2006). Os jogos didáticos proporcionam aos alunos um ensino mais dinâmico, pois são recursos que contribuem para diminuir a barreira que os próprios educandos construíram para se protegerem da formalização das disciplinas exatas, ultrapassando, assim, esse obstáculo a partir de uma motivação e interação com a realidade social. São recursos que motivam e fomentam o processo de desenvolvimento do conhecimento, podendo ser definidos como uma ação prazerosa, independente do contexto linguístico, desconsiderando o objeto envolto na ação (SOARES; OLIVEIRA 2005).Desta forma, o jogo didático, além de ser considerado um dos instrumentos mais importantes no ofício docente, é uma ferramenta que tem a capacidade de instigar a curiosidade, a iniciativa de participação e a autoconfiança do aluno, proporcionando assim, a formação para a cidadania e a aprendizagem significativa.

Assim, diante da necessidade de inovar e aplicar novas metodologias de ensino para tornar as aulas de Química mais interessantes e motivadoras, o presente tra- balho, que faz parte de uma pesquisa mais abrangente, teve como objetivo a construção, a aplicação e a avaliação do jogo didático "Trilha das Funções Orgânica" em uma turma de $3^{\circ}$ ano do ensino médio de uma escola pública cearense com o intuito de auxiliar no processo de ensino e aprendizagem do conteúdo funções orgânicas. Além de melhorar o entendimento de determinado conteúdo, este trabalho também teve a finalidade de aumentar o entrosamento entre aluno-aluno e entre aluno-professor.

\section{FUNDAMENTAÇÃO}

\subsection{Atividades lúdicas no Ensino de Química}

O Ensino de Química ainda é praticado nas escolas de forma arcaica, ou seja, concentrando-se na repetição de nomes e memorização de fórmulas e cálculos, totalmente desvinculado do cotidiano e da realidade na qual os discentes estão inseridos. O modo como a Química é apresentada aos educandos, de forma completamente descontextualizada, torna-a uma disciplina monótona, abstrata e enfadonha, fazendo com que muitos estudantes não se interessem pela mesma. Segundo os pesquisadores Lima e Lima-Neto (1999), a forma como alguns conteúdos de Química são ministrados, faz com que o aluno desenvolva uma concepção completamente equivocada em relação à disciplina de Química, pois muitos estudantes a veem como uma ciência abstrata, uma vez que não conseguem compreender os conceitos de geometria espacial das moléculas, prejudicando assim, o processo de ensino e aprendizagem. Por conseguinte, consta-se que, de modo geral, os jovens não se interessam pela Química, chegando a considerar que tal ciência não faz parte de suas vidas. Sendo assim, fazse necessário que os professores busquem metodologias diferenciadas diretamente relacionadas ao Ensino de Química, com o propósito de incitar o interesse e a importância dos conceitos químicos constantemente presentes nos currículos escolares.

A inserção de jogos e atividades lúdicas no espaço escolar é uma proposta viável que pode contribuir para a mudança no cenário do Ensino tradicional, sobretudo no Ensino de Química. Independentemente do nível de escolaridade, essas atividades auxiliam no crescimento pessoal do discente, bem como sua atuação em colaboração com a comunidade. São também instrumentos que motivam e estimulam o processo de edificação do conhecimento, podendo ser definidos, de acordo com Soares e Oliveira (2005), como uma ação prazerosa, independente do contexto linguístico, desconsiderando o objeto envolto na ação.

Atividades com caráter lúdico tem a finalidade de 
TRILHA DAS FUNÇÕES ORGÂNICAS: UM JOGO DIDÁTICO PARA O ENSINO DE QUÍMICA

fazer com que o aluno desenvolva o intelecto, a capacidade de observação e, por conseguinte, contribuem para o processo de aprendizagem. Além do mais, potencializam as competências e habilidades necessárias às práticas educacionais vigentes. A individualidade de cada aluno deve ser respeitada, cabendo ao professor, no papel de intercessor, propiciar possibilidades na construção do conhecimento. As atividades lúdicas, quando são bem exploradas, facilitam a socialização e a interlocução de saberes (MELO, 2005).

Existem vários tipos de atividades lúdicas para ensinar diversos conceitos em sala de aula, como charadas, quebra-cabeças, problemas diversos, jogos e simuladores, dentre outros. É uma ferramenta que fomenta o interesse inerente ao ser humano e, por consequência, motiva-o para que busque formas alternativas que expliquem e solucionem as atividades propostas (MELO 2005).

A inclusão de jogos e atividades lúdicas na sala de aula proporciona ao indivíduo muitos benefícios em vários aspectos, bem como colabora para o desenvolvimento da aptidão intelectual e promove inúmeros conhecimentos. Nessa linha de pensamento, Maluf (2003, p. 43) comenta:

\footnotetext{
Todo ser humano pode beneficiar-se de atividades lúdicas, tanto pelo aspecto de diversão e prazer quanto pelo aspecto da aprendizagem. Através das atividades lúdicas desenvolvem-se várias capacidades, explora-se e reflete-se sobre a realidade, a cultura na qual se vive e ao mesmo tempo, questionam-se regras e papéis sociais. Pode-se dizer que nas atividades lúdicas ultrapassa-se a realidade, transformando-a através da imaginação. A incorporação de brincadeiras, jogos e brinquedos na prática pedagógica pode desenvolver diferentes atividades que contribuem para inúmeras aprendizagens e ampliação da rede de significados construtivos tanto para crianças como para jovens.
}

Durante o processo de aplicação das atividades lúdicas, os docentes podem analisar traços da personalidade do estudante, bem como de seu desempenho individual e em equipe. Os alunos, ao jogarem, desenvolvem o autoconhecimento de suas responsabilidades e valores, as experiências corporais, a troca de conhecimentos e o aumento da autoestima, através das atividades de socialização (MALUF, 2003). Além disso, as atividades lúdicas estimulam o aluno a raciocinar e a refletir, contribuindo para o desenvolvimento das suas competências e habilidades. Dessa forma, o estudante se sente mais motivado nas aulas de Química, de modo que o lúdico promove a construção dos conhecimentos físico, mental e social (SANTANA; WARTHA, 2006).

\subsection{Os Jogos didáticos como um recurso pedagó- gico no Ensino de Química}

Segundo Soares e Oliveira (2005), o jogo pode ser considerado como qualquer atividade lúdica cujas regras são determinadas pela própria sociedade, de uso comum e tradicionalmente aceito. Os jogos contribuem de forma significativa para o processo de estruturação do conhecimento do educando, além de proporcionarem diversão e estímulo às descobertas (SANTANA; WARTHA, 2006).

Em seus diversos trabalhos, Piaget apresenta fatos e experiências que envolvem o lúdico aplicadas no universo infantil. Para o autor, os jogos vão além de um simples entendimento; são instrumentos que favorecem o crescimento cognitivo, tornando-se mais relevantes à proporção que a criança se desenvolve (NASCIMENTO, 2006).

Os jogos podem ser aplicados no espaço escolar com o objetivo de desenvolver o intelecto de forma indutiva. Dessa forma, o jogo, por ser uma atividade que normalmente é aplicada em equipe, tem grande relevância como integrador social (NASCIMENTO, 2006). Além disso, o jogo proporciona ao educando um relacionamento com a sociedade de forma livre e independente; pois, com o seu uso didático, o professor poderá perceber, através da prática de jogos em sala de aula, aspectos comportamentais de liderança, cooperação, ética, além de possibilitar conhecer como cada um está assimilando o conteúdo escolar (NARDIN, 2008).

Segundo Kishimoto (1994 apud SOARES, 2013), a aplicação do jogo no espaço escolar, além de estabelecer um ambiente propício para a investigação, a exploração e a resolução de problemas, também favorece a aprendizagem através do erro. O benefício do jogo está nessa possibilidade de estimular a exploração em busca de resposta.

Com a finalidade de complementar seus recursos pedagógicos e tornar a aula mais atrativa e dinâmica, os professores têm, nesses últimos anos, utilizado jogos didáticos em salas de aula (SOARES; OLIVEIRA. 2005).Desse modo, o jogo tem um papel primordial no sentido de despertar o interesse do estudante para um conteúdo específico no qual ele sinta dificuldade.

Segundo Kishimoto (1994), no momento em que o jogo é encarado pelo discente como uma brincadeira, ele assimila o conteúdo sem perceber. Assim, é possível perceber uma considerável melhoria nos resultados da aprendizagem em virtude de o jogo ser estimulante, fazendo com que o educando passe do jogo à ação de estudar (NARDIN, 2008).

Uma das principais vantagens observada ao aplicar jogos didáticos no universo escolar é a motiva- 
TRILHA DAS FUNÇÕES ORGÂNICAS: UM JOGO DIDÁTICO PARA O ENSINO DE QUÍMICA

ção, quando gerada pelo desafio, promove o desenvolvimento de estratégias de solução de problemas, a familiarização com definições e termos abordados e a avaliação das decisões tomadas. Além de despertar o interesse dos educandos para algum assunto discutido em sala de aula, os jogos pedagógicos também favorecem um aprendizado eficaz, divertido e empolgante, visto que o conhecimento adquirido de determinados conteúdos através dos jogos, é associado ao lúdico (NARDIN. 2008).

Entretanto, a utilização de jogos sem planejar uma ocasião adequada - que incentive e intervenha na atividade de uma forma mais descontraída e dinâmica não é viável. É necessário que o docente tenha a devida cautela ao utilizar o jogo como uma ferramenta para auxiliar na aprendizagem, a fim de que esse recurso se transforme num estímulo e, dessa forma, possa tornar o aprendizado mais prazeroso e não uma simples disputa ou diversão (NARDIN, 2008).

O trabalho com jogos em todos os seus aspectos, tanto cognitivos quanto afetivos, exige, por parte do docente, planejamento e definição dos objetivos desejados, para que o processo de ensino e aprendizagem ocorra de forma eficaz na sala de aula. É fundamental que haja uma relação harmoniosa entre professores e alunos, de modo que a troca de experiências e opiniões seja verdadeira e proporcione a socialização do conhecimento. Portanto, haverá interação entre a educação escolar e a aquisição de conhecimentos, o que resultará em processos de aprendizagem e desenvolvimento (NARDIN, 2008).

Portanto, os jogos didáticos, quando são devidamente utilizados em sala de aula, apresentam-se como um recurso potencialmente capaz de motivar e facilitar a compreensão de conceitos químicos, uma vez que a aprendizagem é um processo intrínseco do indivíduo com o meio e o outro.

\section{MATERIAIS E MÉTODOS}

O presente trabalho foi realizado através de uma pesquisa de natureza descritiva, de cunho qualiquantitativo, de campo, desenvolvida com 21 alunos do $3^{\circ}$ ano do ensino médio na E.E.F.M Professor Paulo Freire, localizada em Fortaleza-Ceará. Esta pesquisa teve como objetivo elaborar, aplicar e analisar a contribuição do jogo didático "Trilha das Funções Orgânicas" como um instrumento pedagógico para auxiliar no estudo das principais funções orgânicas e suas aplicações no cotidiano, desenvolvendo nos educandos as habilidades em vários aspectos: intelectuais, relacionais e emocionais. Vale ressaltar que, antes da aplicação do jogo em sala de aula, houve a explanação do conteúdo abordado.
A “Trilha das Funções Orgânicas” (Figura 1) é um jogo didático de perguntas e respostas. Foram estruturadas algumas questões mais acessíveis, denominadas "perguntas", e questões com um grau maior de dificuldade, denominadas "problemas". O jogo foi composto por 25 fichas com perguntas sobre as principais funções orgânicas e suas aplicações no cotidiano, distribuídas em 5 cores diferentes e 10 fichas com problemas. Vale ressaltar que todas as questões foram elaboradas com o auxílio do livro didático adotado na escola.

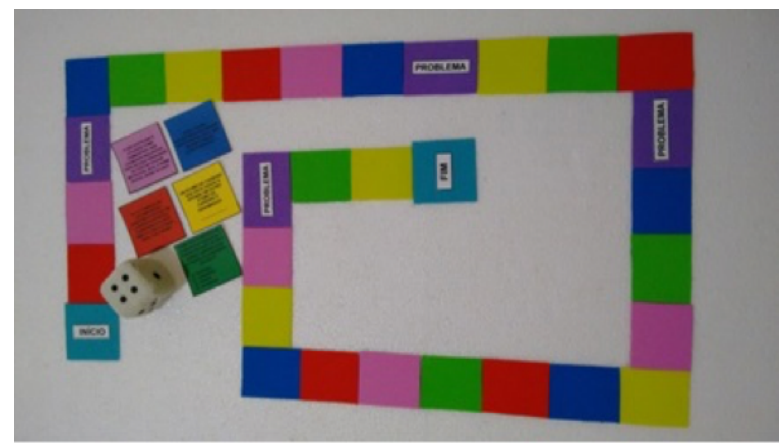

Figura 1: Jogo didático Trilha das Funções Orgânicas

O instrumento didático foi confeccionado utilizando-se E.V.A. (emborrachado) de várias cores, seguindo uma trilha através de um tabuleiro composto por 30 casas coloridas. As questões foram escritas em fichas coloridas, sendo a pergunta feita de acordo com a cor na qual o jogador parou no tabuleiro. O jogo também foi constituído por um dado que foi utilizado para o sorteio do número de casas que o jogador avançou e pinos que representaram os jogadores.

Os 21 alunos que participaram da atividade foram organizados de forma aleatória em três equipes (cada equipe escolheu um representante para responder as perguntas) de sete pessoas e o professor assumiu a função de mediador entre os grupos, esclarecendo as possíveis dúvidas. Inicialmente, foram apresentadas as regras e estratégias do jogo e o conhecimento sobre as funções orgânicas e suas aplicações no cotidiano foi primordial para que o jogador pudesse responder às perguntas e os problemas.

A ordem das equipes foi escolhida através do lançamento de um dado, começando a jogar aquela que tirou o maior número, seguindo o jogo no sentido horário. No tabuleiro, 10 casas continham a palavra "problema". Caso o jogador parasse nessa casa, ele teria que responder a um cartão-problema com questões de nível mais elevado. Acertando, avançaria 5 casas; errando, retrocederia 5 casas. Nas demais casas coloridas, caso o jogador da vez parasse em uma delas, teria 
que responder a um cartão-pergunta. Se a resposta fosse considerada correta, ele avançaria duas casas, caso contrário, retrocederia duas e aguardaria nova vez de jogar. Quem primeiro chegou à última casa, ganhou o jogo. Os demais jogadores continuaram jogando, determinando quem ocupou o $2^{\circ}, 3^{\circ}$ e $4^{\circ}$ lugares (Figura 2).

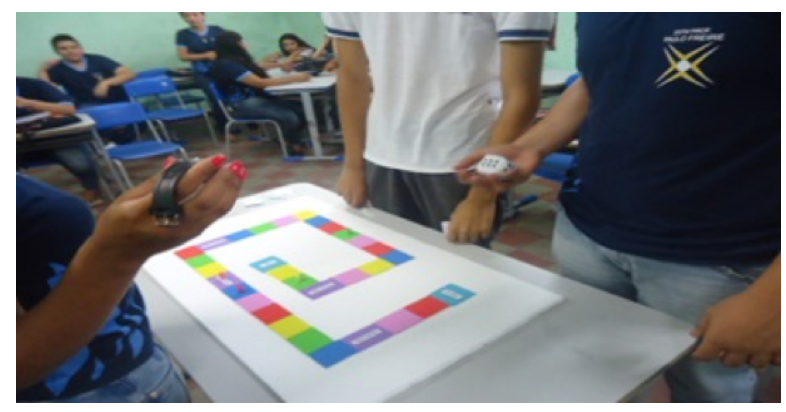

Figura 2: Aplicação do jogo Trilha das Funções Orgânicas em sala de aula.

Após a realização da atividade, foi aplicado um questionário com questões objetivas e subjetivas para avaliar o jogo didático, permitindo conhecer a opinião dos discentes em relação ao mesmo e de que forma o jogo didático "Trilha das Funções Orgânicas" contribuiu, ou não, para auxiliar no estudo das funções orgânicas.Para análise dos dados foi utilizado o Teste Binomial. Em todos os casos foi utilizado o nível de significância de $5 \%(\alpha=0,05)$.

\section{RESULTADOS E DISCUSSÃo}

Os dados que serão apresentados e discutidos a seguir foram obtidos a partir das observações do professor e através das respostas do questionário aplicado aos discentes após a utilização do jogo.

O resultado da análise estatística, realizada com os dados do questionário aplicado aos alunos, encontra-se apresentado na Tabela 1. Para as questões 1, 2 e 3 foi encontrado $\mathrm{p}<0,05$; indicando existir uma diferença significativa entre as respostas. Já para a questão 4 (Dificuldade dos alunos em compreender as regras do jogo), observou-se que suas respostas não foram estatisticamente diferentes ( $\mathrm{p}>0,05)$, não havendo preferência por qualquer das opções apresentadas. É importante reforçar que, em se tratando de jogos voltados para o ensino, as regras desempenham um papel de grande importância, como afirma Soares (2013, p. 41): “caso se queira atingir a aprendizagem de alguns conceitos com o jogo, passa-se primeiramente por regras a serem obedecidas para que o jogo ou a atividade funcionem a contento e se atinjam os objetivos propostos". Por- tanto, para que um jogo funcione de forma adequada em sala de aula, faz-se necessário que as regras sejam claras e bem explicadas; do contrário, tais objetivos não serão alcançados.

Tab 1: Questão 1 - Em que o jogo ajudou? a - Tornar a aula mais atrativa; b - Tornar a aula mais chata; c - Mudar a rotina das aulas tornando-a mais interessante; $\mathrm{d}$ - Assimilar o conteúdo de forma mais sifnificativa; Questão 2 - O jogo didático aplicado melhorou a compressnão do conteúdo das funções orgânicas? a - Sim; b - Não; Questão 3 - O jogo didática aplicado aumentou o interesse pela disciplina de Química? a - Sim; b - Não; Questão 4 - Teve dificuldade em compreender as regras do jogo? a - Sim; b - Não.

\begin{tabular}{llll}
\hline QUESTÕES & $\mathbf{N}^{\mathbf{0}}$ ALUNOS (n) & $\%$ & p-VALOR \\
\hline Questão 1 & & & \\
Resposta a & 4 & $18 \%$ & \\
Resposta b & 0 & $0 \%$ & \\
Resposta c & 9 & $43 \%$ & 0,010 \\
Resposta d & 8 & $39 \%$ & \\
Total & 21 & $100 \%$ & \\
\hline Questão 2 & & & \\
Resposta a & 1 & $6 \%$ & 0,0001 \\
Resposta b & 20 & $94 \%$ & \\
Total & 21 & $100 \%$ & \\
\hline Questão 3 & & & \\
Resposta a & 18 & $87 \%$ & 0,002 \\
Resposta b & 3 & $13 \%$ & \\
Total & 21 & $100 \%$ & \\
\hline Questão 4 & & & \\
Resposta a & 4 & $20 \%$ & 0,999 \\
Resposta b & 17 & $80 \%$ & \\
Total & 21 & $100 \%$ & \\
& & &
\end{tabular}

$\mathrm{Na}$ primeira questão do questionário aplicado, perguntou-se: "Em que o jogo didático Trilha das Funções Orgânicas aplicado em sala de aula ajudou?”. O Gráfico 3 mostra os resultados obtidos:

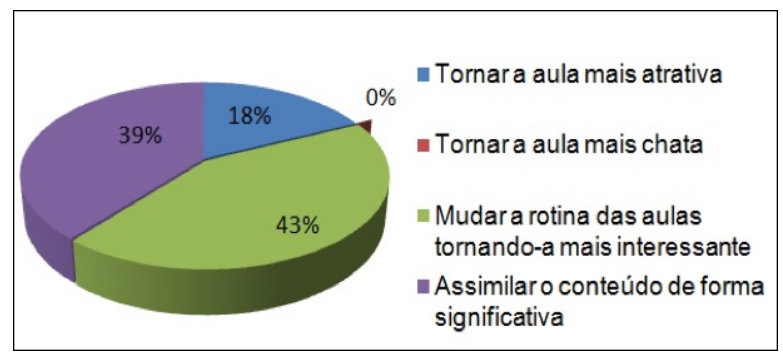

Figura 3: Opiniões dos alunos sobre em que o jogo ajudou.

Analisando os dados do Gráfico 3, verificou-se que a maioria $(43 \%)$ respondeu que o jogo mudou a rotina da aula, tornando-a mais interessante, dinâmica, divertida, fugindo da aula tradicional e saindo da monoto-

\footnotetext{
${ }^{1}$ Teste Binomial, $\mathrm{p}<0,05$ significativo a $5 \%$ de probabilidade.
} 
nia. Ainda, segundo os alunos, a atividade proporcionou uma maior interação entre os colegas, fortalecendo, assim, vínculos de amizade. Os 39\% afirmaram que assimilaram o conteúdo de forma significativa, visto que o jogo aborda o conteúdo - funções orgânicas - relacionando com o dia a dia deles. Os discentes perceberam a importância da Química no seu cotidiano, já que ela está constantemente presente em quase todos os produtos utilizados no dia a dia.

De acordo com Melo (2005), o jogo, além de proporcionar prazer e motivação para o discente, contribui de forma significativa para o processo de edificação da aprendizagem. Os $18 \%$ que responderam que o jogo tornou a aula mais atrativa justificaram-se afirmando que a aula se tornou mais prazerosa e interativa, favorecendo a troca de experiências, o trabalho em equipe e o desenvolvimento individual, social e mental.

Na segunda questão, foi perguntado aos educandos: "O jogo didático aplicado em sala de aula pelo professor atendeu às suas expectativas para melhor compreensão do conteúdo funções orgânicas?”. Os resultados e as respectivas justificativas serão mostrados logo em seguida (Gráfico 4)

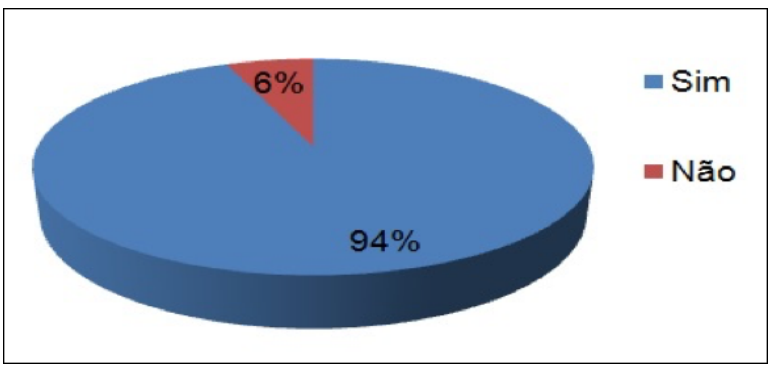

Figura 4: Opinião dos alunos em relação ao jogo didático aplicado para melhorar a compreensão do conteúdo das funções orgânicas.

De acordo com o resultado do Gráfico 4 a maioria dos estudantes (94\%) afirmou que a utilização do jogo didático correspondeu às suas expectativas para auxiliar na assimilação de assuntos complexos em sala de aula, justificando que o mesmo tornou a aula mais atrativa, estimulante, diferenciada, criativa e divertida. Outros afirmaram que aprenderam mais do que imaginavam, pois o trabalho em grupo fez com que adquirissem mais conhecimentos. Alguns responderam que o jogo ajudou a assimilar melhor as funções orgânicas, destacando a importância do professor no momento em que foi preciso auxiliar em alguma dificuldade. Uma minoria (6\%) disse que a atividade não auxiliou na aprendizagem do conteúdo por não gostar e achar o jogo muito complicado.

Eis algumas justificativas dos alunos participantes:

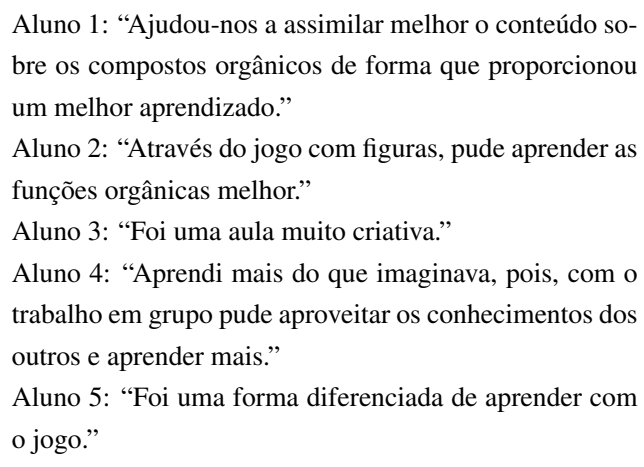

Aluno 5: "Foi uma forma diferenciada de aprender com o jogo."

Os resultados acima comprovam que o jogo funcionou de forma satisfatória no processo de ensino das funções orgânicas e que propiciou interesse ao ensino da Química Orgânica, sendo considerado pelos estudantes como uma atividade lúdica e instigadora, pois houve uma considerável progressão na aprendizagem da maioria dos discentes que apresentavam dificuldades nos conteúdos discutidos durante as aulas. É importante salientar que o conteúdo explorado durante a aplicação do jogo já havia sido abordado nas aulas tradicionais antes da utilização do mesmo, ou seja, os alunos já tinham os conhecimentos prévios sobre o assunto. Campos, Bortoloto e Felício (2003) declaram que os aspectos lúdico e cognitivo inerentes aos jogos são mecanismos relevantes que contribuem para processo de ensino e aprendizagem de diversos conceitos considerados complexos e abstratos, estimulando assim, o desenvolvimento do raciocínio.

$\mathrm{Na}$ terceira questão, foi perguntado aos estudantes: "Com o uso do jogo didático em sala de aula, aumentou seu interesse pela disciplina de Química?" Visualiza-se melhor os resultados obtidos através do Gráfico 5 .

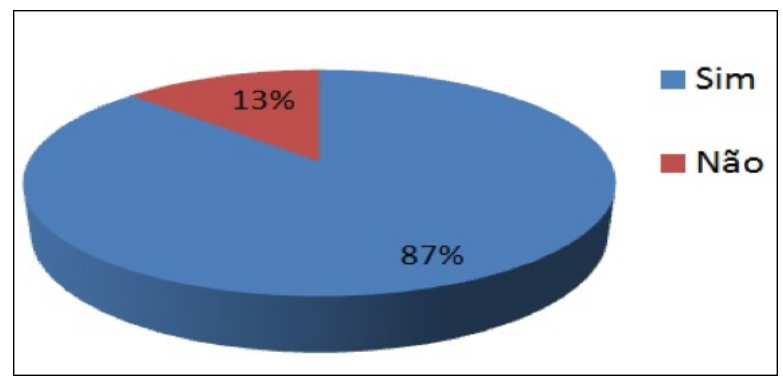

Figura 5: Opiniões dos alunos em relação ao aumento do interesse dos mesmos pela disciplina Química após a utilização do jogo.

Com base nos resultados acima, observou-se que o jogo didático, de fato, despertou o interesse dos alunos pela disciplina de Química, facilitando a sua compreensão, fato que foi observado durante a aplicação da atividade, pois situações que envolvem a ludicidade estimulam o interesse pela aula. De acordo com Bertoldi 
TRILHA DAS FUNÇÕES ORGÂNICAS: UM JOGO DIDÁTICO PARA O ENSINO DE QUÍMICA

(2003), a explicação para esse resultado está no fato de os jogos didáticos oportunizarem a aprendizagem de maneira divertida, dinâmica, diferente da aula tradicional, que, de modo geral, é totalmente desvinculada do cotidiano do estudante. Os $13 \%$ que discordaram justificaram-se alegando o fato de não se interessarem pela disciplina, por não terem prestado atenção nas aulas e por terem dificuldade na compreensão da mesma.

Eis algumas justificativas dos alunos participantes:

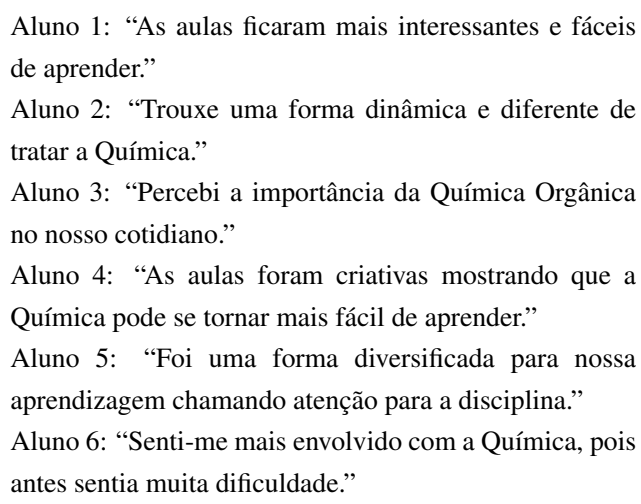

Dessa forma, o jogo apresentou-se como eficaz tanto para motivar quanto para estimular o interesse por parte do alunado para o aprendizado de vários conceitos de Química Orgânica, considerados complexos e abstratos por eles, uma vez que as atividades lúdicas impressionam e proporcionam prazer e dinamismo ao serem realizadas, além de estimularem o senso crítico, a imaginação e a formação de significados, os quais favorecem a aprendizagem. De acordo com Soares, Okumura e Cavalheiro (2003), é necessário que o docente busque recursos didáticos diversificados que proporcionem estímulo e desperte o fascínio dos estudantes pela disciplina de Química.

A quarta questão tinha o seguinte enunciado: "Sentiu alguma dificuldade para compreender as regras ou o desenrolar do jogo?" O Gráfico 6 retrata o percentual dos índices de respostas colhidas:

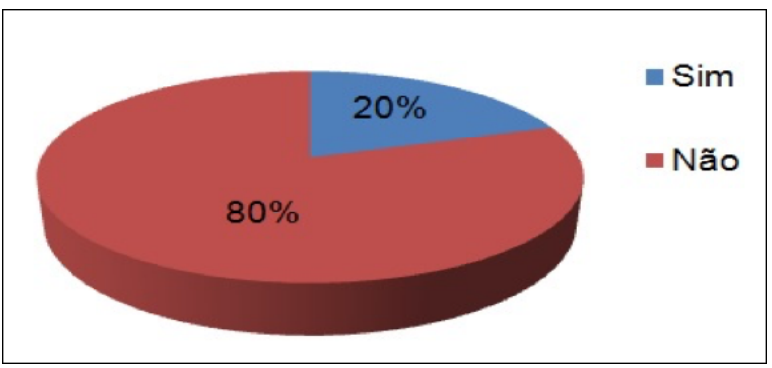

Figura 6: Dificuldade dos alunos em compreender as regras do jogo.
$O$ resultado evidencia que a maioria dos estudantes não sentiu dificuldade na compreensão das regras que foram explicitadas antes de iniciar o jogo. À medida que surgia alguma dúvida em relação às normas, a professora-pesquisadora se prontificava para esclarecêla e elucidar qualquer questionamento que surgisse. É importante destacar que os conhecimentos prévios dos discentes facilitaram a explicação das regras do jogo, bem como ajudaram a dinamizá-los, visto que foram poucas as dúvidas no decorrer da atividade.

$\mathrm{Na}$ quinta questão (subjetiva), foi solicitado aos estudantes que opinassem em relação às vantagens e desvantagens da utilização de jogos didáticos no Ensino de Química. As respostas mais significativas dos discentes em relação às vantagens foram organizadas e transcritas a seguir:

Aluno 1: "Sai um pouco da rotina e as aulas se tornam bem mais interessantes."

Aluno 2: "Melhor compreensão do conteúdo, maior diversão durante a aula e atrativa para todos os alunos, mesmo os que não gostam da matéria."

Aluno 3: "Aulas mais dinâmicas, conteúdo fica mais fácil de aprender, aulas mais interessantes."

Aluno 4: "A integração entre alunos e professores."

Aluno 5: "Ajudou-nos a trabalhar em equipe estimulando o dinamismo entre os colegas."

Algumas das respostas dos discentes em relação às desvantagens foram organizadas e transcritas a seguir:

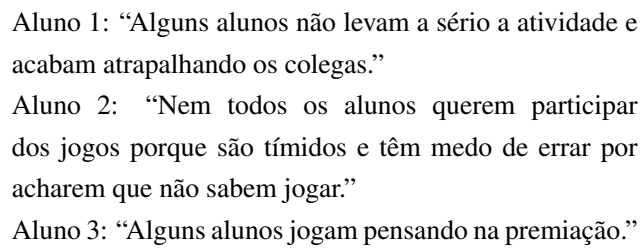

O professor, antes de desenvolver qualquer atividade que envolva jogos didáticos, deve refletir sobre suas vantagens e desvantagens. Entende-se, então, que o sucesso desse recurso didático no universo escolar depende da reflexão do professor quanto à forma de aplicar, às características e à finalidade de cada jogo. Dessa forma, cabe ao educador fazer uma análise e um estudo de modo que fique evidente o porquê da aplicação do jogo para trabalhar alguns conceitos de forma a atingir os objetivos almejados.

$\mathrm{O}$ docente que pretende aplicar jogos didáticos em sala de aula como proposta metodológica deve estudálos e inseri-los em seu plano de aula (GRANDO, 2001). 
TRILHA DAS FUNÇÕES ORGÂNICAS: UM JOGO DIDÁTICO PARA O ENSINO DE QUÍMICA

Para Sousa e Gomes (2013), o uso dos jogos didáticos deveria fazer parte do planejamento de todos os professores, pois proporciona aulas mais dinâmicas e interativas, além de fortalecer o espírito de grupo e da parceria entre aluno-aluno e aluno-professor. Diante disso, o currículo escolar deverá ser alterado, a fim de encaixar espaço de tempo para os jogos e que os mesmos sejam devidamente utilizados como uma alternativa metodológica de aperfeiçoamento de técnicas de aprendizado de conceitos.

\section{CONSIDERAÇÕES FINAIS}

O jogo aplicado neste trabalho foi adaptado para o conteúdo das funções orgânicas e associado ao cotidiano do educando. Com base nos resultados apresentados neste artigo, os jogos didáticos são recursos válidos que podem ser aplicados no Ensino de Química, pois propiciam aos alunos aulas mais lúdicas e interativas, bem como proporcionam o aprofundamento de conceitos aparentemente abstratos, contribuindo para uma aprendizagem contextualizada, ou seja, próxima da realidade do aluno.

Vale ressaltar que os jogos didáticos funcionam como uma ferramenta educacional que leva a um aprendizado mais dinâmico e prazeroso, e favorece o desenvolvimento do raciocínio do discente no que tange aos conceitos de Química. Nessa perspectiva, o docente deverá inserir os jogos em seu plano de aula como um instrumento complementar no processo de ensino e aprendizagem. No entanto, para que o recurso utilizado alcance o objetivo desejado, é imprescindível que o professor planeje previamente e adapte adequadamente os jogos ao perfil dos discentes e aos conteúdos que pretende trabalhar em sala de aula.

De resto, a utilização o jogo didático "Trilha das Funções Orgânicas" aplicado ao ensino das funções orgânicas se apresentou como grande potencial pedagógico para a busca do aprimoramento do processo de aprendizagem do referido conteúdo, ao tempo que promoveu o desenvolvimento de outras habilidades aos alunos como a interatividade, a cooperação e o sentido do trabalho em grupo.

\section{REFERÊNCIAS}

BERTOLDI, M. A escolha dos jogos definida pelas dificuldades específicas de cada criança. Curitiba, 2003.

CAMPOS, L. M. L.; BORTOLOTO, T. M.; FELÍCIO, A. K. C. A produção de jogos didáticos para o ensino de ciências e biologia: uma proposta para favorecer a aprendizagem. 2003. Editora Vozes, 2003.
CARDOSO, S. P.; COLINVAUX, D. Explorando a motivação para estudar química. Química Nova, v. 23, n. 3 , p. $401-404,2000$.

GRANDO, R. C. O jogo na educação: aspectos didático-metodológicos do jogo na educação matemática. 2001

KISHIMOTO, T. M. O jogo e a educação infantil. Revista Perspectiva, v. 12, n. 22, p. 105, 1281994.

LIMA, M. B. P.; LIMA-NETO, P. Construção de modelos para ilustração de estruturas moleculares em aulas de química. Química Nova, v. 22, n. 6, p. 903 906, 1999.

MALUF, A. C. M. Brincar: prazer e aprendizado. :

MELO, C. M. R. As atividades lúdicas são fundamentais para subsidiar ao processo de construção do conhecimento (continuação). Información Filosófica, v. 2, n. 1, p. 128 - 137, 2005.

NARDIN, I. C. B. Brincando aprende-se química. 2008.

NASCIMENTO, T. L. Repensando o Ensino de Química no ensino médio. Fortaleza: , 2006. Trabalgo de Conclusão de Curso (Graduação em Licenciatura em Química).

SANTANA, E. M.; WARTHA, E. J. O ensino de química através de jogos e atividades lúdicas baseados na teoria motivacional de maslow. In: Encontro de pesquisa e ensino de Ciências. Florianópolis: , 2006.

SOARES, M. H. F. B. Jogos e Atividades Lúdicas para o Ensino de Química. : Editora Kelps, 2013.

SOARES, M. H. F. B.; OKUMURA, F.;

CAVALHEIRO, E. T. G. Proposta de um jogo didático para ensino do conceito de equilíbrio químico. Química Nova na Escola, n. 18, p. 13 - 17, 2003.

SOARES, M. H. F. B.; OLIVEIRA, A. S. Júri químico: uma atividade lúdica para discutir conceitos químicos. Química Nova na Escola, n. 21, p. 18 - 24, 2005.

SOUSA, T. P.; GOMES, R. O. A. Jogos lúdicos: recursos didáticos para o ensino de química. Conexões - Ciência e Tecnologia, v. 7, n. 3, p. 44 - 52, 2013. 